Article

\title{
How the Demographic Composition of Academic Science and Engineering Departments Influences Workplace Culture, Faculty Experience, and Retention Risk
}

\author{
Eric E. Griffith ${ }^{1}$ and Nilanjana Dasgupta ${ }^{2, *}$ \\ 1 Department of Anthropology, University of Massachusetts, Amherst, MA 01003, USA; \\ ericg@anthro.umass.edu \\ 2 Department of Psychological \& Brain Sciences, University of Massachusetts, Amherst, MA 01003, USA \\ * Correspondence: dasgupta@psych.umass.edu; Tel.: +1-413-545-0049
}

Received: 15 December 2017; Accepted: 10 April 2018; Published: 24 April 2018

\begin{abstract}
Although on average women are underrepresented in academic science, technology, engineering, and mathematics (STEM) departments at universities, an underappreciated fact is that women's representation varies widely across STEM disciplines. Past research is fairly silent on how local variations in gender composition impact faculty experiences. This study fills that gap. A survey of STEM departments at a large research university finds that women faculty in STEM are less professionally satisfied than male colleagues only if they are housed in departments where women are a small numeric minority. Gender differences in satisfaction are largest in departments with less than $25 \%$ women, smaller in departments with $25-35 \%$ women, and nonexistent in departments approaching 50\% women. Gender differences in professional satisfaction in gender-unbalanced departments are mediated by women's perception that their department's climate is uncollegial, faculty governance is non-transparent, and gender relations are inequitable. Unfavorable department climates also predict retention risk for women in departments with few women, but not in departments closer to gender parity. Finally, faculty who find within-department mentors to be useful are more likely to have a favorable view of their department's climate, which consequently predicts more professional satisfaction. Faculty gender and gender composition does not moderate these findings, suggesting that mentoring is equally effective for all faculty.
\end{abstract}

Keywords: gender; STEM; climate; retention; faculty

\section{Introduction}

Knowledge production in academia relies on a community of scholars who are satisfied with their work environment, committed to their institution, and productive in research, teaching, and service. In fields like the sciences, technology, engineering, and mathematics (STEM), satisfaction, and productivity of faculty play vital roles in ensuring that scientific discovery and innovation flourish in the nation. Put differently, workplace satisfaction and productivity of faculty in science and engineering have beneficial effects at the societal level. Given this, it is particularly concerning that professional satisfaction among university faculty in the United States often reveals persistent gender disparities. On average, women in STEM fields tend to feel significantly less satisfied with their professional life than their male colleagues (Callister 2006; Ong et al. 2011; Settles et al. 2006, 2007; Xu 2008).

A large body of research shows that STEM departments are different from non-STEM departments in terms of organizational demographics and the prevalence of gender role stereotypes. Women faculty and students comprise a numeric minority in STEM departments, and these disciplines tend to view men 
(more than women) as disciplinary experts (Carli et al. 2016; Dasgupta and Stout 2014; Nosek et al. 2002). Minority status and stereotypes associating scientific expertise with maleness contribute to an unsupportive climate for women faculty, reducing their professional satisfaction, and increasing their risk of attrition relative to male colleagues (Blackwell et al. 2009; Callister 2006; Corley 2005; Fox 2010; Greene et al. 2010; Hillard et al. 2014; Xu 2008).

Importantly, the research summarized above tacitly assumes uniformity in the demographics of STEM departments. No prior research has examined whether the relation between workplace climate, professional satisfaction, and retention risk varies across STEM departments with different gender compositions. This is an important issue to address because, in actuality, there is considerable variation in the gender composition of faculty across STEM fields. An examination of national statistics from the National Science Foundation (2013) data reveal that in some disciplines, such as computer science and engineering, women comprise $13.4 \%$ and $14 \%$ of tenure-track faculty, respectively, whereas in life science disciplines women comprise $34 \%$ of tenure-track faculty, and in behavioral science departments like psychology, women comprise 55\% of tenure-track faculty (National Science Foundation 2013). In short, women's representation in STEM fields varies widely depending on the specific discipline. If being outnumbered by male colleagues in STEM negatively affects women's professional satisfaction as suggested by prior research, then sizeable variations in the demographic composition of departments ought to produce sizeable variations in the climate of those departments and, in turn, impact faculty members' professional satisfaction and retention risk.

Surprisingly, little or no research has examined how local variations in gender composition within academic units impact workplace climate, and whether this climate subsequently predicts faculty satisfaction and turnover intentions. Our research aims to address this unanswered question and others that follow from it. Specifically, three hypotheses guide this work. First, we predict that the gender of faculty in STEM and variations in faculty gender composition across STEM departments will influence (a) the climate of those departments; (b) faculty's professional satisfaction; and (c) faculty intentions to leave the institution. Second, we predict that the negative impact of skewed gender composition on professional satisfaction and retention risk will be mediated through deficits in department climate. Third, we predict that faculty mentoring will serve as an effective intervention to improve department climate and, in turn, enhance professional satisfaction and retention risk.

\subsection{Gender Differences in Perceived Workplace Climate and Professional Satisfaction: Past Research}

Perceived workplace climate has been defined and operationalized in multiple ways-there is no single agreed upon definition or one widely accepted measure in the research literatures in psychology, organizational behavior, and sociology. Some studies have defined climate in terms of overall positive or negative interpersonal relations among faculty and measured it using items with positive and negative evaluative labels (e.g., friendly vs. hostile, cooperative vs. competitive, collegial vs. uncollegial, sexist vs. egalitarian; Hurtado 1998; Settles et al. 2006; Blackwell et al. 2009; Riffle et al. 2013). Others have defined climate purely in terms of social exclusion (August and Waltman 2004; Maranto and Griffin 2011). Yet others have defined and measured climate in terms of workload and productivity such as time allocation to specific professional tasks, research productivity, and work/life balance (Blackwell et al. 2009; Callister 2006; Hillard et al. 2014; Settles et al. 2006). Finally, another group of papers included department and institutional support and job satisfaction in their definition of climate (Britton and Logan 2008; Gardner 2012; Riffle et al. 2013).

The demographics and disciplines of faculty members who served as research participants in past studies on workplace climate also varied widely. Some studies compared STEM faculty who are men and women (Blackwell et al. 2009; Callister 2006; Hillard et al. 2014; Xu 2008), while others compared men and women from both STEM and non-STEM departments (Britton et al. 2012; Gardner 2012; Maranto and Griffin 2011; Riffle et al. 2013) and yet others surveyed only women faculty across all departments (August and Waltman 2004; Settles et al. 2006). 
Comparisons of men and women faculty within STEM revealed that, on average, women had more negative experiences than men in their departments: women felt their departments were less supportive (Blackwell et al. 2009), less collegial and respectful (Corley 2005), less welcoming (August and Waltman 2004; Greene et al. 2010), and they felt less valued and more marginalized (Fox 2010; Massachusetts Institute of Technology Committee on Women Faculty 1999). Women in STEM also spent less time on research than men and were asked to do more teaching and service (Carrigan et al. 2011; Massachusetts Institute of Technology Committee on Women Faculty 1999). Experiencing negative department climate predicted more intentions to quit for women compared to men (Callister 2006; Gardner 2012), despite being equally committed to their professional career as their male counterparts (Callister 2006; Greene et al. 2010; Riffle et al. 2013; Xu 2008). These gender differences were erased when workplace climate was statistically controlled (Callister 2006; Greene et al. 2010; Xu 2008) and when women felt they had a voice in their department (Settles et al. 2007). All these past studies aggregated faculty responses across all types of STEM disciplines and did not compare faculty responses from different departments.

In other studies that surveyed both STEM and non-STEM faculty, women differed from men across disciplines on some dimensions. Specifically, women perceived less fairness in personnel action such as the tenure and promotion process (Gardner 2012), felt more excluded (Maranto and Griffin 2011), perceived lower levels of collegiality, respect, and value (Riffle et al. 2013), and felt less satisfied in academia than men (for reviews see Bozeman and Gaughan 2011; Ceci et al. 2014). Gender differences in professional satisfaction were mediated by perceived department climate, such that when workplace climate was statistically controlled the difference in satisfaction between women and men was erased (Britton et al. 2012).

Finally, a comparison of women faculty in STEM versus non-STEM departments showed that STEM women perceived their departments to be less welcoming (Blackwell et al. 2009), and were less satisfied with their department climate (Britton and Logan 2008) than their non-STEM women colleagues. Collectively, these findings suggest that less favorable workplace climate in academic departments is associated with lower professional satisfaction and greater retention risk. Moreover, women, especially those in STEM fields, are disproportionately affected.

\subsection{The Influence of Workplace Gender Composition on Women and Men: Past Research}

Much of the research on gender composition in the workplace draws on Kanter (1977) classic theory of tokenism, which proposes that members of an extreme minority within a workplace $(15 \%$ or less of the total group) will be perceived through the lens of group-based stereotypes rather than being seen as unique individuals. Kanter argued that when workplaces become less demographically skewed thereby reducing tokenism, the organizational climate is likely to improve and discrimination decreases. In other words, when the proportion of women reaches "critical mass" in the workplace (defined as $25-30 \%$ of the workplace) the organizational climate should improve, according to Kanter's theory.

Tokenism theory, however, has not uniformly stood up to rigorous empirical testing. On the positive side, some research on academic institutions suggests that reaching a critical mass of women faculty in academic departments does have benefits. For example, as STEM workplaces approach numeric gender balance, women report more positive perceptions of career advancement (Hillard et al. 2014), increased professional satisfaction (Carrigan et al. 2011), report more equitable resource distribution (Etzkowitz et al. 2000), and fair salaries (Michelmore and Sassler 2016). In contrast, when women are in very small numbers they are more likely to face gender inequities and procedural unfairness (Maranto and Griffin 2011). In nonacademic workplaces, gender equity in numbers has also been credited with improved performance evaluations for women (Lortie-Lussier and Rinfret 2002; Sackett et al. 1991), enhanced innovation on corporate boards (Torchia et al. 2011), more equitable personnel decisions (Heilman 1980) and decreased marginalization of women politicians (Childs and Krook 2008).

However, different from Kanter's theory, increasing the proportion of women in academic departments has also been associated with some negative outcomes. Some research found that as the 
proportion of women in academic departments increased, men's satisfaction with the workplace environment decreased (Collins 1998; Etzkowitz et al. 2000; Henwood 1996; Kirchmeyer 1995), women's turnover increased (Tolbert et al. 1995) and women's salaries in high-level administrative positions decreased (Pfeffer and Davis-Blake 1987). Moreover, nonfaculty staff members at academic institutions appear less satisfied in departments with numeric gender balance compared to other departments with mostly men (Wharton et al. 2000). In nonacademic workplaces, increase in numeric equity among employees in terms of gender and race increased negative reactions from White and male employees (Tsui et al. 1992), and sometimes hurt workplace climate (Allmendinger and Hackman 1995; Pelled 1996; South et al. 1982).

Taken together, these data suggest that although achieving critical mass may begin to reduce gender inequities, it also might trigger resistance and backlash from dominant group members who may anticipate losing status and resources (Acker 1990; Carrigan et al. 2011; Etzkowitz et al. 2000; Reskin et al. 1999). Overall, "the paradox of critical mass" acknowledges that an increase in the proportion of women in a department does not necessarily solve problems encountered by women who are a minority group in academia (Etzkowitz et al. 2000).

An important source of ambiguity in this literature is inconsistent operationalization of gender composition that muddies the interpretation of research findings. Some studies defined gender composition as the proportion of women in a specific workplace-a department or a work unit-who interact with each other (Hillard et al. 2014; Maranto and Griffin 2011; Wharton et al. 2000). However, others define it as the proportion of women faculty within a national cohort in a given field (Carrigan et al. 2011; Michelmore and Sassler 2016) or the proportion of PhDs conferred to women in a given field nationally (Britton et al. 2012). The latter two definitions of gender composition have little bearing on women's opportunities to interact with each other in a workplace and thus are unlikely to affect women's professional lives in their local workplace whereas gender composition operationalized as the proportion of women and men in a local workplace ought to have an impact on professional lives. Treating these two operational variables as the same construct (gender composition) may explain why this literature is so mixed.

The inconsistent findings may also be a result of research using different measures of climate and professional satisfaction. For example, Hillard et al. (2014) measured department climate using three metrics: opportunities for women's advancement, perceived discrimination, and time spent on service. They found that in departments with few women, female faculty perceived fewer opportunities for women's advancement than did their male colleagues but department gender composition did not impact gender differences in time spent on service or perceived discrimination. To the best of our knowledge, no prior published research has investigated whether the gender composition of STEM workplaces (e.g., academic departments) influences individuals' satisfaction and turnover intentions. The present study seeks to fill this gap.

\subsection{Mentoring as a Solution?}

Mentoring among faculty has often been suggested as a successful process by which institutions can promote career development and success of its faculty (Kram and Isabella 1985; Long and Fox 1995; Sands et al. 1991; Sorcinelli and Yun 2007). Mentors introduce young faculty into professional networks critical for success; help them learn unwritten rules of professional life; identify what work is valued in their workplace; and how to access resources necessary for research and teaching (Kemelgor and Etzkowitz 2001). In other words, mentoring enhances mentees' institutional connectedness and promotes career development through informal acquisition of knowledge. Mentoring has also been linked to objective benefits such as accelerated promotion and higher pay (Allen et al. 2004), and higher levels of retention and grant funding (Gardiner et al. 2007). Given the benefits, it is surprising that many academic departments do not provide mentorship programs for faculty (Riffle et al. 2013; Zellers et al. 2008). 
Faculty mentoring appears to be important for both women and men (Boice 1993; Riffle et al. 2013). Regardless of gender, faculty report that mentoring improved their time allocation and self-efficacy (Feldman et al. 2010), understanding of the promotion process (Chung et al. 2010), and overall job satisfaction (Bilimoria et al. 2006; Wasserstein et al. 2007; Mullen and Hutinger 2008). Despite these generally gender-uniform results, some research suggests that the mentoring experience may differ subtly for men and women - women explicitly connect mentoring they have experienced with higher levels of productivity and a greater sense of connectedness to their institution (Waltman 2001). And some have argued that women in gender-skewed academic departments may be most in need of mentorship because they may face a more negative department climate (Ragins 1999; Wallace 2001; Settles et al. 2007).

Of course, the effectiveness of mentoring hinges on successful pairings of mentors and mentees (Cullen and Luna 1993). Some studies suggest that women benefit more from male mentors because men, being advantaged, confer organizational legitimacy on their mentees and provide resources required for success (Dreher and Cox 1996; Ragins and Sundstrom 1989; Wallace 2001). Conversely, other studies argue that for women, female mentors are more likely to enhance social belonging, empowerment, and provide psychosocial support (Dasgupta 2011; Dennehy and Dasgupta 2017; Ragins and McFarlin 1990; Settles et al. 2007).

The present study advances past research on mentoring in two ways. First, we investigate whether mentoring benefits all faculty regardless of gender, or benefits women more, given their underrepresentation in STEM. Second, we explore whether the gender composition of STEM departments influences the impact of mentoring-specifically, do women who are in tiny numbers in some STEM departments benefit more from mentoring than other women in other departments that are less gender skewed?

\subsection{Overview of the Present Research}

We conducted a survey of faculty in academic science and engineering departments at a large research university. Our survey included both women and men, and faculty of all ranks. Faculty were recruited from all departments in the physical sciences, life sciences, psychological and brain sciences, mathematics and statistics, engineering, and computer science. These academic departments varied widely in gender composition, and were classified into three groups defined by the percentage of women faculty within each department: (1) departments with less than $25 \%$ women; (2) departments with $25-35 \%$ women; and (3) departments with $36-55 \%$ women (see Table 1). No academic department in STEM had more than $55 \%$ women faculty.

To recap, three overarching hypotheses guided this research. First, we predict that the gender of faculty in academic science and engineering and variations in department gender composition will influence: (a) workplace climate; (b) faculty members' professional satisfaction; and (c) faculty members' intentions to stay at or leave the institution. In other words, in departments with very few women relative to men, women faculty (compared to male colleagues) are likely to experience their workplace climate as being less positive; feel less satisfied with their professional life; and think of leaving the institution more often. These differences between women and men are not expected to emerge when the gender composition of departments is less skewed. Second, we predict that variations in workplace climate will mediate and explain why skewed gender composition in departments has detrimental impacts on professional satisfaction and turnover intentions. Third, we hypothesize that peer-to-peer faculty mentoring will improve department climate and, in turn, improve satisfaction and reduce turnover intentions. We explore whether the benefits of mentoring vary by faculty gender or by department gender composition or if it is equally useful across the board. 
Table 1. Department Gender Composition.

\begin{tabular}{cccc}
\hline $\begin{array}{c}\text { Departments with Less than 25\% } \\
\text { Women Faculty }\end{array}$ & $\begin{array}{c}\text { Total Faculty in the } \\
\text { Department }\end{array}$ & $\begin{array}{c}\text { Female } \\
\text { Faculty }\end{array}$ & \% Female \\
\hline Computer Science & 47 & 6 & $12.77 \%$ \\
Civil Engineering & 28 & 4 & $14.29 \%$ \\
Physics & 31 & 5 & $16.13 \%$ \\
Agriculture & 23 & 4 & $17.39 \%$ \\
Mathematics & 55 & 10 & $18.18 \%$ \\
Chemical Engineering & 20 & 4 & $20.00 \%$ \\
Astronomy & 13 & 3 & $23.08 \%$ \\
Chemistry & 33 & 8 & $24.24 \%$ \\
\hline Departments with 25-35\% & Total Faculty in the & Female & $\%$ Female \\
women faculty & department & Faculty & \\
\hline Environmental Conservation & 32 & 9 & $28.13 \%$ \\
Biochemistry & 18 & 9 & $33.33 \%$ \\
Geosciences & 26 & 7 & $34.62 \%$ \\
Microbiology & 20 & Female & \% \\
Departments with 36-54\% & Total Faculty in the & 5 \\
\hline women faculty & department & 15 & $38.46 \%$ \\
\hline Food Science & 13 & 10 & $39.47 \%$ \\
Biology & 38 & 28 & $50.00 \%$ \\
Veterinary \& Animal Sciences & 20 & $\mathbf{1 3 3}$ & $\mathbf{2 8 . 3 6 \%}$ \\
\hline Psychological \& Brain Sciences & 52 & &
\end{tabular}

\section{Materials and Methods}

\subsection{Participants}

Faculty members from a large public research university in the Northeastern United States (U.S.) were recruited to participate in a survey about their professional experiences at the university $(N=383)$. Recruitment was accomplished using a multipronged strategy. The corresponding author made announcements at each department's faculty meeting and at a dean's meeting for department heads and chairs. The dean also sent emails to all faculty in STEM departments urging them to participate in the survey. Faculty recruitment was specific to life sciences, psychological and brain sciences, physical sciences, mathematics and statistics, engineering, and computer science. ${ }^{1}$ In total, $82 \%$ of all faculty in above-mentioned STEM departments (383 out of a total 467 faculty) completed the survey, which is a very high response rate. Of this sample, $62.1 \%$ were men ( $n=238), 32.4 \%$ were women $(n=124), .3 \%$ were gender non-binary $(n=1)$, and $5.2 \%$ percent did not answer the gender question $(n=20)$. In terms of rank, $41.0 \%$ were full professors $(n=157), 17.2 \%$ associate professors $(n=66), 18.5 \%$ assistant professors $(n=71), 12.5 \%$ lecturers $(n=48), 5.2 \%$ non-tenure-track research faculty $(n=20)$, and $5.5 \%$ did not answer the question $(n=21)$. In terms of race/ethnicity, $81.7 \%$ were White $(n=313), 12.0 \%$ Asian $(n=46), 1 \%$ African American or Black $(n=4), 1.8 \%$ multiracial or other ethnicities $(n=7)$, and $3.4 \%$ did not answer the question $(n=13)$. Additionally, $4.2 \%$ identified as Latino or Hispanic $(n=16), 92.4 \%$ were not Latino or Hispanic $(n=354)$, and $3.4 \%(n=13)$ did not answer the question. Taken together, $18.5 \%$ of faculty in this sample self-identified as members of racial/ethnic minority groups $(n=71)$, and $5 \%$ of the sample identified as members of underrepresented groups (Black or Hispanic, $n=20)$. In terms of national origin, $65.8 \%$ percent were U.S. born $(n=252), 30 \%$

1 The focus of the present study was on STEM departments known to have fewer women than men because of our a priori hypothesis that gender composition would play an important role in guiding faculty satisfaction. Thus, we recruited faculty from the College of Natural Sciences, College of Engineering, and College of Computer and Information Sciences at the university. Psychological and Brain Sciences resides within the College of Natural Sciences at this university and thus faculty from this department was recruited as well. Other social science departments (economics, sociology, political science, and anthropology) are located in the College of Social and Behavioral Sciences and were not included in this study. 
were immigrants $(n=115)$, and $4.2 \%$ did not answer the question $(n=16)$. Overall, this sample was representative of the population of STEM faculty at this university.

\subsection{Measures and Procedures}

After providing informed consent the survey was administered online via Qualtrics. Participants were assured that their responses were confidential and only the authors of this paper would be privy to individual-level data, which would not be shared with department chairs, university leaders, or other faculty. Only aggregated summary findings were shared with department chairs, deans, other campus leaders, and all faculty. No deception was employed. The survey assessed several aspects of faculty professional experiences at the university: (1) professional satisfaction in terms of research, teaching, and service; (2) perception of the culture and climate of their home department; (3) experience being mentored by other faculty at this university; (4) retention risk; and (5) demographics. All survey items reported in this manuscript are included as Supplementary Material and available online.

\subsubsection{Professional Satisfaction}

Three questions asked participants to evaluate how satisfied they were with their research, teaching, and professional interactions with faculty colleagues on five-point scales ranging from 1 (very dissatisfied) to 5 (very satisfied). Three additional questions asked participants to evaluate how valued they felt in their department for their research, teaching, and service, on five-point scales ranging from 1 ("not at all valued") to 5 ("extremely valued").

\subsubsection{Department Culture and Climate}

Faculty perception of department culture and climate was assessed using 16 questions. Of these, eight questions focused on collegiality and fairness. These items asked respondents to evaluate the degree to which their department was collegial, collaborative, cooperative, inclusive, supportive, equitable, fair, and respectful on a series of bipolar scales ranging from -2 to +2 anchored by positive and negative words.

Four additional questions asked participants to evaluate faculty governance in their department -specifically, the degree of transparency in decision-making related to policies, procedures, and personnel actions (e.g., tenure and promotion, merit raises, etc.). Participants responded to three governance questions on five-point scales ranging from 1 ("not at all transparent") to 5 ("very transparent"). A fourth item asked faculty to report how often they were asked to take on important leadership roles in the department on a scale of 1 ("never") to 5 ("always").

Two questions were dedicated to gender equity, inquiring about how similarly or differently men and women faculty were treated in the department. Participants responded on a five-point scale ranging from 1 ("women often get preferential treatment") to 5 ("men often get preferential treatment"); the midpoint of the scale, 3 , represented gender equality ("men and women get treated equally"). Two additional questions were dedicated to race equity, inquiring about how similarly or differently faculty of different races and ethnicities were treated in the department. Participants responded on a five-point scale ranging from 1 ("racial minority faculty often get preferential treatment") to 5 ("white faculty often get preferential treatment"); the midpoint of this scale, 3, represented racial equality ("white and racial minority faculty get treated equally").

\subsubsection{Retention Risk}

One question assessed whether faculty participants had ever considered leaving the university. Responses to this question were measured using a single categorical variable ("yes" or "no"). 


\subsubsection{Peer Mentoring for Faculty}

Experiences of being mentored by other faculty at this university were measured with three questions. Participants were asked if they had a faculty mentor at the university either in their home department or in a different department at the university (2 items, with "yes" and "no" as the response options). They were asked to indicate the degree to which their experience being mentored was useful to their career ( 2 items) on five-point scales ranging from 1 ("not at all useful") to 5 ("very useful"). We also asked respondents for the gender of their faculty mentors (two items) and whether they chose their mentors, or had mentors assigned (two items).

\section{Results}

\subsection{Descriptive Statistics: Department Gender Composition}

Departments were grouped into three gender composition categories based on the proportion of women in each category: (1) Departments with less than 25\% women; (2) departments with $25 \%$ to $35 \%$ women; (3) departments with $36 \%$ to $54 \%$ women. Department gender composition was determined by examining faculty rosters for each STEM department during the academic year 2014-2015 when this survey was administered. Eight of 16 departments had less than $25 \%$ women faculty (12-24\%); these were Computer Science, Engineering, Physics, Agriculture, Mathematics and Statistics, Astronomy, and Chemistry, which align with national trends (National Science Foundation 2013). Four of 16 departments had $28 \%$ to $35 \%$ women faculty; they were Environmental Conservation, Biochemistry, Geosciences, and Microbiology. The remaining four departments came close to, or achieved, gender parity (38-54\% women). They were Food Science, Biology, Veterinary and Animal Sciences, and Psychological and Brain Sciences. See Table 1 for a complete list of all departments with information about their gender composition.

\subsection{Creation of Composite Variables for Department Climate and Professional Satisfaction}

An exploratory principal components analysis (PCA) was conducted with Varimax rotation to reduce the 16 variables assessing department climate into a smaller number of thematic clusters based on conceptual meaning as well as inter-item correlations. The PCA returned four rotated factors with eigenvalues greater than 1 that, together, accounted for $67 \%$ of the total variance and captured meaningful themes. First, overall climate of the department accounted for $42 \%$ of variance in responses and consisted of eight items: collegiality, collaboration, cooperation, inclusion, support, equity, fairness, and respect (this factor was labeled overall department climate). Second, transparency of faculty governance and decision-making accounted for $12 \%$ of variance in responses and comprised four items: transparency of promotion criteria, transparency of decision-making processes in the department, faculty members' willingness to communicate their concerns to department chair or head, and inclusion of all faculty in department governance (this factor was labeled transparency of decision-making). Third, perceived gender equity in the department accounted for $6 \%$ of variance and comprised two items that measured whether male and female faculty were treated similarly or differently (this factor was labeled gender equity). Finally, perceived race equity in the department accounted for $7 \%$ of variance in responses and comprised two items that measured whether White and racial/ethnic minority faculty were treated similarly or differently (this factor was labeled race equity).

The primary dependent variable of interest was professional satisfaction, which comprised six items measuring how satisfied and valued faculty felt in their department in relation to their research, teaching, and service. The three items for feeling valued in the department and three items relating to professional satisfaction were all intercorrelated $(\alpha=0.79)$ and were averaged into a single index labeled overall professional satisfaction. 
3.3. Does Gender of Faculty Respondents and the Gender Composition of Their Departments Influence Perceived Department Climate?

We conducted several Analyses of Variance (ANOVAs) using faculty gender (male, female) $\times$ department gender composition (less than 25\%, 25-35\%, 36-54\%) as between-participant factors. The four dependent variables used in these ANOVAs assessed different aspects of department climate (see below). These analyses only included faculty who indicated their gender as male or female; those who chose, "other," "prefer not to answer," or did not answer this question were filtered out of these analyses. Because the number of racial/ethnic minority faculty in this sample was very small (18.5\%), we were unable to statistically explore whether the experiences of women faculty of color compared to White women were different in departments with varying gender compositions.

\subsubsection{Overall Department Climate}

A significant main effect of faculty gender showed that women felt their department climate was significantly less positive $(M=3.78, S E=0.09)$ than men $\operatorname{did}(M=3.99, S E=0.06), F(1,351)=6.10$, $p=0.01$. Another significant main effect of department gender composition indicated that participants in departments with very few women $(<25 \%$ women and $25-35 \%$ women) felt their department's climate was less favorable $(M=3.80, S E=0.08$; and $M=3.89, S E=0.08$, respectively) than others in departments closer to gender parity (36-54\% women; $M=4.23, S E=0.09), F(2,351)=7.71, p<0.01$. Both main effects were superseded by a marginal two-way interaction between faculty gender $\times$ department gender composition, $F(1,351)=2.45, p=0.09$. Follow-up $t$-tests conducted to disaggregate this interaction effect showed that the gender gap between women and men's perceptions of department climate was significantly bigger for departments that had less than $25 \%$ women $\left(M_{\text {male }}=3.94, S E=0.08\right.$, $M_{\text {female }}=3.34, S E=0.21 ; p=0.01$, Cohen's $\left.d=0.63\right)$ and $25-35 \%$ women $\left(M_{\text {male }}=4.00, S E=0.09\right.$, $M_{\text {female }}=3.69, S E=0.14 ; p=0.05$, Cohen's $\left.d=0.32\right)$; but no gender difference emerged when the department gender ratio was close to or at parity (36-54\% women: $M_{\text {male }}=4.19, S E=0.15, M_{\text {female }}=4.26$, $S E=0.11 ; p=0.70$, Cohen's $d=0.09$; see Table 2 for all statistics). For women, the differences followed a significant linear trend, $F(2,120)=14.3, p<0.01$, rather than a sharp uptick at critical mass, suggesting that incremental improvement in numbers toward gender parity has incremental benefits on overall department climate. The linear trend did not exist for men, $F(2,231)=1.78, p<0.18$. 
Table 2. Influence of gender and department gender composition on department climate.

\begin{tabular}{|c|c|c|c|c|c|c|c|c|}
\hline \multirow{2}{*}{$\begin{array}{l}\text { Department } \\
\text { Culture and } \\
\text { Climate }\end{array}$} & \multicolumn{5}{|c|}{ Dept. Gender Composition } & \multicolumn{2}{|c|}{ Main Effects } & \multirow{2}{*}{$\begin{array}{c}\begin{array}{c}\text { Interaction } \\
\text { Effect }\end{array} \\
\text { Gender } \times \\
\text { Dept. Gender } \\
\text { Composition }\end{array}$} \\
\hline & $\begin{array}{l}\text { Participant } \\
\text { Gender }\end{array}$ & $\begin{array}{c}\text { Gender } \\
\text { Composition: } \\
<25 \% \text { Female }\end{array}$ & $\begin{array}{c}\text { Gender } \\
\text { Composition: } \\
25-35 \% \\
\text { FEMALE }\end{array}$ & $\begin{array}{c}\text { Gender } \\
\text { Composition: } \\
36-55 \% \text { Female }\end{array}$ & $\begin{array}{c}\text { Mean } \\
\text { Response }\end{array}$ & $\begin{array}{l}\text { Main Effect of } \\
\text { Gender }\end{array}$ & $\begin{array}{l}\text { Main Effect of } \\
\text { Dept. Gender } \\
\text { Composition }\end{array}$ & \\
\hline \multirow{3}{*}{ Climate } & Male & $\begin{array}{l}M=3.94 \\
S D=0.86\end{array}$ & $\begin{array}{l}M=4.00 \\
S D=0.92\end{array}$ & $\begin{array}{l}M=4.19 \\
S D=0.77\end{array}$ & $\begin{array}{l}M=3.99 \\
S D=0.88\end{array}$ & \multirow{3}{*}{$\begin{array}{c}F(1,351)=6.10 \\
p=0.01\end{array}$} & \multirow{3}{*}{$\begin{array}{c}F(2,351)=7.71 \\
\quad p=0.0005\end{array}$} & \multirow{3}{*}{$\begin{array}{c}F(2,351)=2.49 \\
p=0.09\end{array}$} \\
\hline & Female & $\begin{array}{l}M=3.34 \\
S D=1.17\end{array}$ & $\begin{array}{l}M=3.69 \\
S D=1.06\end{array}$ & $\begin{array}{l}M=4.26 \\
S D=0.74\end{array}$ & $\begin{array}{l}M=3.78 \\
S D=1.06\end{array}$ & & & \\
\hline & Total & $\begin{array}{l}M=3.80 \\
S D=0.98\end{array}$ & $\begin{array}{l}M=3.89 \\
S D=0.98\end{array}$ & $\begin{array}{l}M=4.23 \\
S D=0.75\end{array}$ & $\begin{array}{l}M=3.92 \\
S D=0.95\end{array}$ & & & \\
\hline \multirow{3}{*}{ Transparency } & Male & $\begin{array}{l}M=3.82 \\
S D=0.75\end{array}$ & $\begin{array}{l}M=3.62 \\
S D=0.74\end{array}$ & $\begin{array}{l}M=3.57 \\
S D=0.72\end{array}$ & $\begin{array}{l}M=3.70 \\
S D=0.74\end{array}$ & \multirow{3}{*}{$\begin{array}{c}F(1,347)=11.60 \\
\quad p=0.0007\end{array}$} & \multirow{3}{*}{$\begin{array}{c}F(2,347)=0.123 \\
\quad p=0.88\end{array}$} & \multirow{3}{*}{$\begin{array}{c}F(2,347)=3.85 \\
p=0.02\end{array}$} \\
\hline & Female & $\begin{array}{l}M=3.16 \\
S D=0.98\end{array}$ & $\begin{array}{l}M=3.46 \\
S D=0.70\end{array}$ & $\begin{array}{l}M=3.46 \\
S D=0.56\end{array}$ & $\begin{array}{l}M=3.38 \\
S D=0.75\end{array}$ & & & \\
\hline & Total & $\begin{array}{l}M=3.67 \\
S D=0.85\end{array}$ & $\begin{array}{l}M=3.56 \\
S D=0.72\end{array}$ & $\begin{array}{l}M=3.51 \\
S D=0.63\end{array}$ & $\begin{array}{l}M=3.59 \\
S D=0.76\end{array}$ & & & \\
\hline \multirow{3}{*}{ Gender Equity } & Male & $\begin{array}{l}M=2.96 \\
S D=0.61\end{array}$ & $\begin{array}{l}M=2.97 \\
S D=0.42\end{array}$ & $\begin{array}{l}M=2.93 \\
S D=0.36\end{array}$ & $\begin{array}{l}M=2.96 \\
S D=0.51\end{array}$ & \multirow{3}{*}{$\begin{array}{c}F(1,350)=60.52 \\
p=8.3 \times 10^{-14}\end{array}$} & \multirow{3}{*}{$\begin{array}{c}F(2,350)=5.64 \\
p=0.004\end{array}$} & \multirow{3}{*}{$\begin{array}{c}F(2,350)=5.21 \\
p=0.006\end{array}$} \\
\hline & Female & $\begin{array}{l}M=3.76 \\
S D=0.82\end{array}$ & $\begin{array}{l}M=3.37 \\
S D=0.49\end{array}$ & $\begin{array}{l}M=3.25 \\
S D=0.49\end{array}$ & $\begin{array}{l}M=3.43 \\
S D=0.62\end{array}$ & & & \\
\hline & Total & $\begin{array}{l}M=3.14 \\
S D=0.74\end{array}$ & $\begin{array}{l}M=3.11 \\
S D=0.48\end{array}$ & $\begin{array}{l}M=3.12 \\
S D=0.47\end{array}$ & $\begin{array}{l}M=3.12 \\
S D=0.59\end{array}$ & & & \\
\hline \multirow{3}{*}{ Race Equity } & Male & $\begin{array}{l}M=2.98 \\
S D=0.27\end{array}$ & $\begin{array}{l}M=2.98 \\
S D=0.29\end{array}$ & $\begin{array}{l}M=2.91 \\
S D=0.46\end{array}$ & $\begin{array}{l}M=2.97 \\
S D=0.30\end{array}$ & \multirow{3}{*}{$\begin{array}{c}F(1,323)=16.58 \\
p=5.9 \times 10^{-5}\end{array}$} & \multirow{3}{*}{$\begin{array}{c}F(2,323)=1.94 \\
\quad p=0.15\end{array}$} & \multirow{3}{*}{$\begin{array}{c}F(2,323)=3.65 \\
p=0.03\end{array}$} \\
\hline & Female & $\begin{array}{l}M=3.23 \\
S D=0.68\end{array}$ & $\begin{array}{l}M=3.02 \\
S D=0.56\end{array}$ & $\begin{array}{l}M=3.29 \\
S D=0.61\end{array}$ & $\begin{array}{l}M=3.15 \\
S D=0.61\end{array}$ & & & \\
\hline & Total & $\begin{array}{l}M=3.03 \\
S D=0.39\end{array}$ & $\begin{array}{l}M=2.99 \\
S D=0.41\end{array}$ & $\begin{array}{l}M=3.12 \\
S D=0.58\end{array}$ & $\begin{array}{l}M=3.03 \\
S D=0.44\end{array}$ & & & \\
\hline
\end{tabular}




\subsubsection{Transparency of Decision-Making}

Another ANOVA using decision-making transparency as the dependent variable revealed similar effects as the prior ANOVA. A significant main effect of faculty gender showed that women felt their department's decision-making process was less transparent $(M=3.38, S E=0.07)$ than men $(M=3.70, S E=0.05), F(1,347)=11.60, p<0.01$. The main effect of department gender composition was nonsignificant, $F(2,347)=0.12, p=0.88$. More importantly, a significant two-way interaction between faculty gender $\times$ department gender composition, $F(2,347)=3.85, p=0.02$, indicated that the gender gap between women and men's perceptions of their department's decision-making transparency was substantial if their department had very few women faculty $\left(<25 \%\right.$ women: $M_{\text {male }}=3.82, S E=0.07$, $M_{\text {female }}=3.16, S E=0.18 ; p<0.01$, Cohen's $\left.d=0.82\right)$, but no such gender difference in opinion emerged in departments with relatively more women (25-35\% women: $M_{\text {male }}=3.62, S E=0.07, M_{\text {female }}=3.46$, $S E=0.10 ; p=0.20$, Cohen's $d=0.22)$ or departments that were close to gender parity (36-54\% women: $M_{\text {male }}=3.57, S E=0.14, M_{\text {female }}=3.46, S E=0.09 ; p=0.49$, Cohen's $d=0.18$; see Table 2 for details).

\subsubsection{Perceived Gender Equity}

Similar to prior analyses, when perceived gender equity was the dependent variable, a significant main effect of faculty gender composition showed that women thought men received preferential treatment in their department $(M=3.43, S E=0.05)$, whereas men thought that both genders were treated equally $(M=2.96, S E=0.03), F(1,350)=60.52, p<0.01$. Another significant main effect of department gender composition $(F(2,350)=5.64, p<0.01)$ indicated that participants in departments with less than $25 \%$ women were more likely to think that men received preferential treatment $(M=3.14$, $S E=0.06)$ than others in departments with $25-35 \%$ women $(M=3.11, S E=0.04)$ or $36-54 \%$ women $(M=3.12, S E=0.06)$. Both main effects were superseded by a significant two-way interaction between gender $\times$ department gender composition, $F(2,350)=5.21, p=0.01$, indicating that the gender gap between women and men's perceptions of department gender equity was biggest if their department had very few women faculty $\left(<25 \%\right.$ women: $M_{\text {male }}=2.96, S E=0.06, M_{\text {female }}=3.76, S E=0.15 ; p<0.01$, Cohen's $d=1.21)$. This effect was smaller but still significant in departments with relatively more women (25-35\% women: $M_{\text {male }}=2.97, S E=0.04, M_{\text {female }}=3.37, S E=0.07 ; p<0.01$, Cohen's $d=0.90$; $36-54 \%$ women: $M_{\text {male }}=2.93, S E=0.07, M_{\text {female }}=3.25, S E=0.08 ; p<0.01$, Cohen's $d=0.74$; see Table 2).

\subsubsection{Perceived Race Equity}

For race equity we also found a significant main effect of faculty gender showing that women (regardless of their own race) thought White faculty received preferential treatment in their departments $(M=3.15, S E=0.06)$ while men perceived no race inequity $(M=2.97, S E=0.02)$, $F(1,323)=16.58, p<0.01$. The main effect of department gender composition was nonsignificant, $F(2,323)=1.94, p=0.15$. Although we found a significant two-way interaction between gender $\times$ department gender composition, $F(2,323)=3.65, p=0.03$, the shape of this interaction effect was different from prior analyses and unpredicted. The gap between women and men's perceptions of racial equity was substantial for departments with very few women faculty ( $<25 \%$ women: $M_{\text {male }}=2.98$, $S E=0.03, M_{\text {female }}=3.23, S E=0.14 ; p=0.09$, Cohen's $\left.d=0.66\right)$, as well as departments close to gender parity (35-54\% women: $M_{\text {male }}=2.91, S E=0.09, M_{\text {female }}=3.29, S E=0.10 ; p<0.01$, Cohen's $\left.d=0.69\right)$. Surprisingly, when gender composition was in-between (25-35\%), men and women perceived racial equity in their department $\left(M_{\text {male }}=2.98, \mathrm{SE}=0.03, M_{\text {female }}=3.02, S E=0.08, p=0.62\right.$, Cohen's $d=0.10$; see Table 2). This result is unexpected and different from all others so we are cautious about interpreting it unless it is replicated in the future. It is possible that this unexpected result for perceived race equity may be due to the race of faculty responding to the survey from departments of varying gender composition. Because the numbers of faculty of color in this sample was very small, we were unable to explore this speculation statistically. 
3.4. Does Gender of Faculty Respondents and Gender Composition of Their Department Influence Professional Satisfaction? If So, Is This Effect Mediated by Department Climate?

In order to test the above-mentioned hypotheses, we conducted a series of mediational tests using the PROCESS macro (Hayes 2013) within the Statistical Package for the Social Sciences SPSS. PROCESS is a computational tool commonly used to conduct moderation and mediation statistical analyses as well as their combination. In our mediational analyses, faculty gender was entered as the independent variable, overall professional satisfaction was the dependent variable, and each of four department climate variables was entered as a proposed mediator in separate analyses (overall department climate, transparency of decision-making, gender equity, race equity). This resulted in four permutations of the model (see Figure 1 for a conceptual diagram).

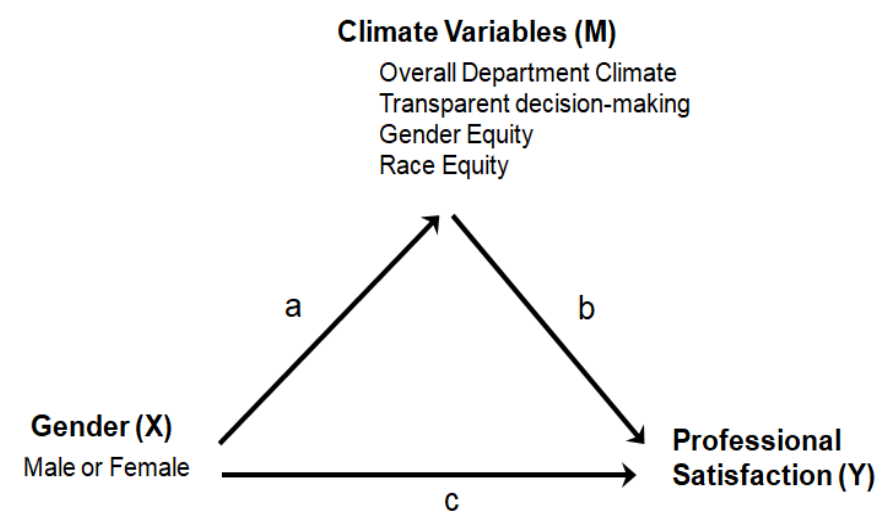

Figure 1. Conceptual mediational model examining whether gender differences in faculty members' professional satisfaction is mediated by differential perceptions of department climate.

The first mediational test showed that women perceived the overall climate in their department to be less favorable than men $(B=-0.20, S E=0.11, p=0.06)$, and negative department climate, in turn, predicted less professional satisfaction $(B=0.47, S E=0.03, p<0.01)$. The indirect effect of faculty gender on professional satisfaction through department climate as a mediator was significant $(B=-0.09, S E=0.05, C I=-0.20,0.00)$.

Two additional PROCESS models showed significant indirect effects of faculty gender on professional satisfaction through transparent decision-making as a mediator $(B=-0.15, S E=0.05$, $C I=-0.26,-0.07)$ and perceived gender equity as a mediator $(B=-0.08, S E=0.04, C I=-0.26,-0.07)$, but perceived race equity was not a significant mediator $(B=-0.01, S E=0.02, C I=-0.06,0.03)$. In other words, women perceived their department climate to be less collegial, less gender equitable, and viewed faculty governance as less transparent than did their male colleagues. All three climate variables mediated and predicted less professional satisfaction. See Table 3 for all statistical details.

Table 3. Gender differences in perceived climate and professional satisfaction.

\begin{tabular}{|c|c|c|c|c|c|}
\hline \multirow{2}{*}{$\begin{array}{l}\text { Independent } \\
\text { Variable }(X)\end{array}$} & \multirow{2}{*}{$\begin{array}{l}\text { Mediator } \\
\text { (M) }\end{array}$} & \multirow{2}{*}{$\begin{array}{l}\text { Outcome } \\
\text { (Y) }\end{array}$} & a path & b path & c path \\
\hline & & & $\mathbf{X} \rightarrow \mathbf{M}$ & $\mathbf{M} \rightarrow \mathbf{Y}$ & $X \rightarrow Y$ \\
\hline \multirow{4}{*}{ Gender } & General Climate & \multirow{4}{*}{$\begin{array}{c}\text { Professional } \\
\text { Satisfaction }\end{array}$} & $B=0.20(0.11),+$ & $B=0.47(0.03)^{* *}$ & $B=-0.14(0.06)^{*}$ \\
\hline & Transparency & & $B=-0.30(0.08)^{* *}$ & $B=0.51(0.04)^{* *}$ & $B=-0.07(0.06), n s$ \\
\hline & Gender Equity & & $B=0.48(0.06)^{* *}$ & $B=-0.19(0.07)^{*}$ & $B=-0.15(0.08)^{*}$ \\
\hline & Race Equity & & $B=0.18(0.05)^{* *}$ & $B=-0.03(0.09), n s$ & $B=-0.18(0.08)^{*}$ \\
\hline
\end{tabular}

Note: $B$ represents unstandardized regression coefficients; numbers in parentheses are standard errors; $n s$ represents nonsignificant regression coefficients. ${ }^{* *} p<0.01,{ }^{*} p<0.05,+p<0.10$. 
Gender Differences in Perceived Climate and Professional Satisfaction Depend on Department Gender Composition: Moderated Mediations

Once it was clear that women vs. men's differential experiences of department climate influenced overall professional satisfaction, we conducted moderated mediations to test if the mediations described above would only hold true in departments where women faculty were a very small minority (see Figure 2 for a conceptual model). In the moderated mediation analyses that follow, gender composition was the predicted moderator of the path between faculty gender and climate ("a" path) and the path between faculty gender and professional satisfaction ("c" path).

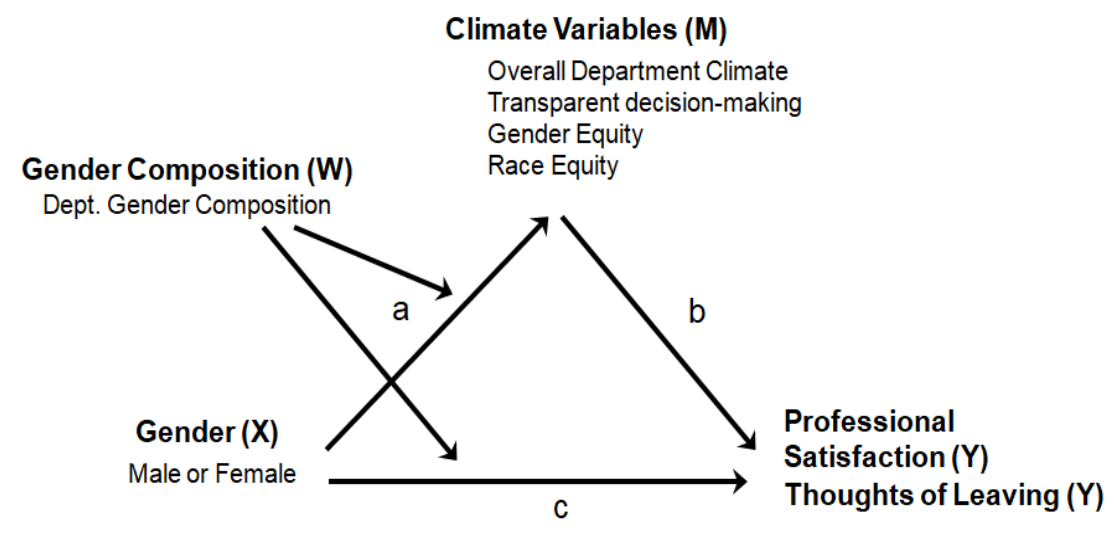

Figure 2. Conceptual model of moderated mediation examining whether gender differences in faculty members' professional satisfaction/thoughts of leaving as mediated by differential perceptions of departmental climate varies by department gender composition.

Results showed that gender composition of the department had a significant moderating effect on the " $c$ " path, such that in departments with few women (less than $25 \%$ or $25-35 \%$ ), women faculty compared to men faculty felt significantly less satisfied with their professional work and this effect was mediated through negative department climate $(<25 \%$ women: $B=-0.29, S E=0.09, C I=-0.50,-0.13$; $25-35 \%$ women: $B=-0.16, S E=0.06, C I=-0.29,-0.05)$. But in departments that approached equal gender representation, the mediation became nonsignificant (36-54\% women: $B=-0.02, S E=0.06$, $C I=-0.14,0.09)$. See Table 4 for all statistical details. 
Table 4. Moderated mediation: Gender differences in perceived climate and professional satisfaction, as moderated by department gender composition.

\begin{tabular}{|c|c|c|c|c|c|c|c|c|c|c|}
\hline \multirow{2}{*}{$\begin{array}{l}\text { Independent } \\
\text { Variable (X) }\end{array}$} & \multirow{2}{*}{$\begin{array}{c}\text { Moderating } \\
\text { Variable(s) }(W)\end{array}$} & \multirow{2}{*}{$\begin{array}{l}\text { Mediator } \\
\text { (M) }\end{array}$} & \multirow{2}{*}{$\begin{array}{c}\text { Outcome } \\
\text { (Y) }\end{array}$} & \multirow{2}{*}{$\begin{array}{c}\text { a path } \\
X \rightarrow M\end{array}$} & \multirow{2}{*}{$\begin{array}{c}\mathbf{a}^{\prime} \text { path } \\
\mathrm{X}^{*} \mathrm{~W} \rightarrow \mathrm{M}\end{array}$} & \multirow{2}{*}{$\begin{array}{l}\text { b path } \\
M \rightarrow Y\end{array}$} & \multirow{2}{*}{$\begin{array}{l}\text { c path } \\
X \rightarrow Y\end{array}$} & \multicolumn{3}{|c|}{$\mathbf{a}^{*} \mathbf{b}$ path (Indirect Effect) } \\
\hline & & & & & & & & $<25 \%$ Female & 25-35\% Female & $36-54 \%$ Female \\
\hline \multirow{4}{*}{ Gender } & \multirow{4}{*}{$\begin{array}{l}\text { Dept. Gender } \\
\text { Composition }\end{array}$} & $\begin{array}{l}\text { General } \\
\text { Climate }\end{array}$ & \multirow{4}{*}{$\begin{array}{l}\text { Professional } \\
\text { Satisfaction }\end{array}$} & $\begin{array}{c}B=-1.06 \\
(0.30) * *\end{array}$ & $\begin{array}{l}B=0.40 \\
(0.15)^{* *}\end{array}$ & $\begin{array}{l}B=0.47 \\
(0.03)^{* *}\end{array}$ & $\begin{array}{c}B=-0.14 \\
(0.06)^{*}\end{array}$ & $\begin{array}{c}B=-0.30(0.10), C I: \\
\quad-0.51,-0.13\end{array}$ & $\begin{array}{c}B=-0.16(0.06), C I: \\
-0.29,-0.05\end{array}$ & $\begin{aligned} B= & -0.02(0.06), C I: \\
& -0.14,0.09\end{aligned}$ \\
\hline & & Transparency & & $\begin{array}{c}B=-0.86 \\
(0.24)^{* *}\end{array}$ & $\begin{array}{l}B=0.30 \\
(0.12)^{*}\end{array}$ & $\begin{array}{l}B=0.53 \\
(0.04)^{* *}\end{array}$ & $\begin{array}{l}B=-0.07 \\
(0.07), n s\end{array}$ & $\begin{aligned} B= & -0.29(0.09), C I: \\
& -0.46,-0.13\end{aligned}$ & $\begin{array}{c}B=-0.17(0.05), C I: \\
-0.29,-0.07\end{array}$ & $\begin{aligned} B= & -0.06(0.05), C I: \\
& -0.17,0.05\end{aligned}$ \\
\hline & & Gender Equity & & $\begin{array}{l}B=1.05 \\
(0.17)^{* *}\end{array}$ & $\begin{array}{c}B=-0.28 \\
(0.08)^{* *}\end{array}$ & $\begin{array}{c}B=-0.19 \\
(0.07) * *\end{array}$ & $\begin{array}{c}B=-0.15 \\
(0.08) \dagger\end{array}$ & $\begin{aligned} B= & -0.14(.07), C I: \\
& -0.30,-0.03\end{aligned}$ & $\begin{aligned} B= & -0.10(0.05), C I: \\
& -0.21,-0.2\end{aligned}$ & $\begin{aligned} B= & -0.06(0.03), C I: \\
& -0.14,-0.01\end{aligned}$ \\
\hline & & Race Equity & & $\begin{array}{l}B=0.01 \\
(0.15), n s\end{array}$ & $\begin{array}{c}B=0.09 \\
(0.07), n s\end{array}$ & $\begin{array}{c}B=-0.05 \\
(0.09), n s\end{array}$ & $\begin{array}{c}B=-0.18 \\
(0.08)^{*}\end{array}$ & $\begin{aligned} B= & -0.01(0.02), C I: \\
& -0.07,0.01\end{aligned}$ & $\begin{aligned} B= & -0.01(0.02), C I: \\
& -0.06,0.02\end{aligned}$ & $\begin{aligned} B= & -0.01(0.03), C I: \\
& -0.07,0.04\end{aligned}$ \\
\hline \multirow{4}{*}{ Gender } & \multirow{4}{*}{$\begin{array}{l}\text { Dept. Gender } \\
\text { Composition }\end{array}$} & $\begin{array}{l}\text { General } \\
\text { Climate }\end{array}$ & \multirow{4}{*}{$\begin{array}{l}\text { Thoughts of } \\
\text { Leaving }\end{array}$} & $\begin{array}{c}B=-0.93 \\
(0.30)^{* *}\end{array}$ & $\begin{array}{l}B=0.36 \\
(0.15)^{*}\end{array}$ & $\begin{array}{l}B=0.45 \\
(0.15)^{* *}\end{array}$ & $\begin{array}{c}B=0.17 \\
(0.26), n s\end{array}$ & $\begin{aligned} B= & -0.24(0.13), C I: \\
& -0.57,-0.06\end{aligned}$ & $\begin{array}{c}B=-0.13(0.07), C I: \\
-0.33,-0.02\end{array}$ & $\begin{aligned} B= & -0.02(0.06), C I: \\
& -0.16,0.10\end{aligned}$ \\
\hline & & Transparency & & $\begin{array}{c}B=-0.79 \\
(0.35)^{* *}\end{array}$ & $\begin{array}{l}B=0.29 \\
(0.12)^{*}\end{array}$ & $\begin{array}{c}B=-0.06 \\
(0.16), n s\end{array}$ & $\begin{array}{c}B=0.08 \\
(0.25), n s\end{array}$ & $\begin{array}{c}B=0.03(0.08), C I: \\
-0.13,0.21\end{array}$ & $\begin{array}{c}B=0.02(0.05), C I: \\
-0.07,0.13\end{array}$ & $\begin{array}{c}B=0.00(0.02), C I: \\
-0.02,0.09\end{array}$ \\
\hline & & Gender Equity & & $\begin{array}{l}B=1.06 \\
(0.18)^{* * *}\end{array}$ & $\begin{array}{c}B=-0.30 \\
(0.09)^{* *}\end{array}$ & $\begin{array}{c}B=-0.21 \\
(0.23), n s\end{array}$ & $\begin{array}{c}B=0.18 \\
(0.27), n s\end{array}$ & $\begin{aligned} B= & -0.15(0.17), C I: \\
& -0.51,0.15\end{aligned}$ & $\begin{aligned} B= & -0.11(0.12), C I: \\
& -0.35,0.11\end{aligned}$ & $\begin{aligned} B= & -0.06(0.07), C I: \\
& -0.21,0.06\end{aligned}$ \\
\hline & & Race Equity & & $\begin{array}{c}B=-0.02 \\
(0.14), n s\end{array}$ & $\begin{array}{c}B=0.08 \\
(0.07), n s\end{array}$ & $\begin{array}{c}B=0.23 \\
(0.31), n s\end{array}$ & $\begin{array}{c}B=0.17 \\
(0.27), n s\end{array}$ & $\begin{aligned} B= & 0.01(0.04), C I: \\
& -0.02,0.15\end{aligned}$ & $\begin{aligned} B= & 0.03(0.04), C I: \\
& -0.03,0.13\end{aligned}$ & $\begin{aligned} B= & 0.04(0.06), C I: \\
& -0.04,0.20\end{aligned}$ \\
\hline
\end{tabular}

Note: $B$ represents unstandardized regression coefficients; numbers in parentheses are standard errors; ns represent nonsignificant regression coefficients; and $C I$ represent $\pm 95 \%$ confidence intervals. Confidence intervals that do not straddle zero are statistically significant whereas confidence intervals that do include zero are nonsignificant. ${ }^{* *} p<0.01$, ${ }^{*}<0.05$, $+p<0.10$. 
Similarly, when decision-making transparency was a mediator, the gender composition of the department significantly moderated the mediation, such that in departments with few women (less than 25\% and 25-35\%), women faculty felt less satisfied with their professional work relative to male peers, an effect that was mediated through less transparent departmental decision-making ( $<25 \%$ women: $B=-0.28, S E=0.08, C I=-0.45,-0.12 ; 25-35 \%$ women: $B=-0.17, S E=0.05$, $C I=-0.27,-0.07)$. But in departments that approached equal gender representation, this mediation was nonsignificant (36-54\% women: $B=-0.06, S E=0.05, C I=-0.16,0.05$ ).

When gender equity was a mediator, gender composition of the department significantly moderated the mediation such that in departments with very few women, women faculty were less satisfied with their professional work relative to their male peers, an effect that was mediated through perceived gender inequity ( $<25 \%$ women: $B=-0.14, S E=0.07, C I=-0.29,-0.02)$. This mediation effect was smaller in magnitude but still significant in departments with 25-35\% women $(B=-0.10, \mathrm{SE}=0.05, C I=-0.21,-0.02)$ and departments with $36-54 \%$ women $(B=-0.06, S E=0.03$, $C I=-0.14,-0.01)$.

In summary, as hypothesized, the moderated mediations confirmed that in departments with large gender imbalance in numbers, women's lower satisfaction with their professional life at the university relative to their male colleagues was substantially influenced by an unfavorable department climate, less transparent faculty governance, and less gender equity in specific types of STEM departments. Departments that had equal (or close to equal) proportions of women and men faculty were less likely to be plagued by unfavorable department climate, non- transparent faculty governance, and less gender equity, which predicted equal professional satisfaction experienced by women and men faculty.

3.5. Does Gender of Faculty Respondents and Gender Composition of Their Department Influence Intentions to Leave the Institution? If So, Is This Effect Mediated by Department Climate?

Given that departmental gender composition and respondents' gender jointly influenced professional satisfaction, and was mediated by an unfavorable department climate, it makes sense that dissatisfaction may extend to faculty members thinking about leaving the institution. To test this hypothesis, we conducted four separate moderated mediations to test whether faculty gender (independent variable) would predict thoughts of leaving (dependent variable), mediated by each of four department climate variables. Department gender composition was used as a moderator of the path between faculty gender and climate (" $a$ " path) as well as between faculty gender and thoughts of leaving (" $c$ " path) (see Figure 2 for a conceptual model).

The mediational test showed that overall department climate mediated women's intentions to leave the institution more than men, as hypothesized, but other aspects of department climate did not have the same impact. Specifically, women perceived the overall climate in their department to be less favorable than did men $(B=-0.93, S E=0.30, p<0.01)$; negative department climate, in turn, predicted more thoughts of leaving the university $(B=0.45, S E=0.15, p<0.01)$. Gender composition of departments significantly moderated the above mediation such that in departments with few women, women faculty were more likely to have considered leaving the institution than their male colleagues ( $<25 \%$ women: $B=-0.24, S E=0.13, C I=-0.57,-0.06 ; 25-35 \%$ women: $B=-0.13$, $S E=0.07, C I=-0.33,-0.02)$; but this mediation was nonsignificant in departments that approached equal gender representation (35-54\% women: $B=-0.02, S E=0.06, C I=-0.16,0.10$ ).

Decision-making transparency, gender equity, and race equity were not significant mediators for retention risk (see Table 4 for statistics). These null effects suggest that when it comes to intentions to leave the university, the overall collaborative and inclusive atmosphere of a department may play a more important role than specific aspects of climate related to faculty governance and gender or race equity. 


\subsection{Can Faculty Mentoring Improve Professional Satisfaction by Improving Climate?}

As part of faculty development, a peer mentoring initiative had been launched at this university in which faculty volunteered as peer mentors to other colleagues as they navigated their careers in academic science and engineering. We sought to assess whether accessing mentoring opportunities, and satisfaction with mentoring relationships, would influence faculty members' perceptions of department climate, and if this in turn would enhance their professional satisfaction. Of the 350 faculty who answered the mentoring questions, $62.4 \%$ had peer mentors on-campus $(n=238)$. Of them, $41.8 \%$ of faculty had mentors both inside and outside their department $(n=100), 31.4 \%$ had mentors in their home department only $(n=110)$, and $8.0 \%$ had mentors outside their department only $(n=28)$. The remaining $32.0 \%$ had no mentors at the university $(n=112)$. Since the focus of the present study was on climate and satisfaction within home departments, we restricted mentoring analyses to participants who had at least one mentor in their department $(n=210 ; 118$ men, 83 women, 1 gender non-binary person, and 8 did not disclose their gender). Sixty percent of men in this subsample indicated they had male mentors only $(n=71), 10.2 \%$ had female mentors only $(n=12), 27.1 \%$ had mentors of both genders $(n=32)$, and three did not indicate the gender of their mentors. Thirty-five percent of the women in this subsample indicated they had male mentors only $(n=29), 21.7 \%$ had female mentors only $(n=18), 42.2 \%$ had mentors of both genders $(n=35)$, and one did not indicate the gender of her mentors. ${ }^{2}$ Of the entire subsample, $60.9 \%$ chose their mentors $(n=128), 16.7 \%$ had mentors assigned to them $(n=35), 21.4 \%$ had both assigned and chosen mentors $(n=45)$, and two participants did not answer the question. Regardless of gender, those who chose their mentors found the relationships to be significantly more useful than those who had mentors assigned $\left(M_{\text {chose }}=4.18\right.$, $S E=0.08, M_{\text {assigned }}=3.39, S E=0.21 ; p<0.01$, Cohen's $\left.d=0.74\right)$.

In order to test whether faculty mentoring improves professional satisfaction through improvement in department climate, we conducted a series of mediational tests using the PROCESS model for SPSS in which the usefulness of mentoring relationships was entered as the independent variable, professional satisfaction was the dependent variable, and the four department climate variables were mediating variables (overall perceived climate, transparency, gender equity, race equity) in separate analyses. This resulted in four permutations of the model (see Figure 3).

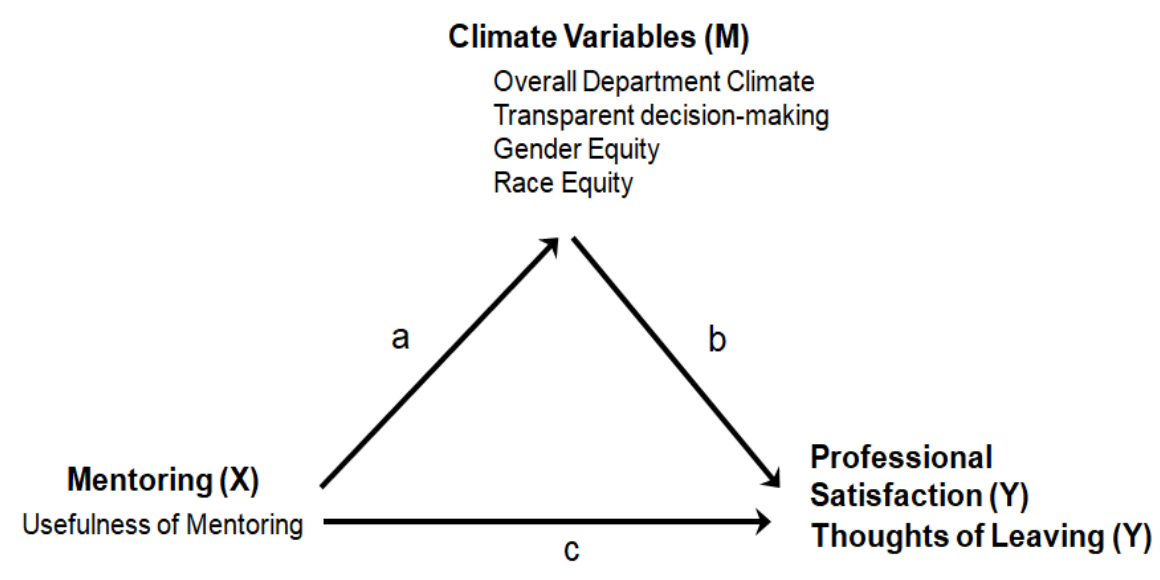

Figure 3. Conceptual mediational model examining whether the effect of faculty mentoring on professional satisfaction/turnover risk is mediated by differential perceptions of department climate.

2 Because the number of female mentors was small (given the low numbers of women in STEM departments overall), we could not use mentor gender in our statistical analyses. 


\subsubsection{Overall Professional Satisfaction}

The first mediational test showed that faculty with mentors who viewed their mentoring relationships as useful had a more favorable view of their department climate $(B=0.19, S E=0.06$, $p<0.01)$, and were also more satisfied with their professional life $(B=0.07, S E=0.04, p=0.03)$. The effect of mentoring on professional satisfaction was significantly mediated through favorable department climate (indirect effect: $B=0.09, S E=0.03, C I=0.04,0.16$ ), as hypothesized. See Table 5 for statistical details.

Table 5. Effect of mentoring on professional satisfaction and thoughts of leaving, as well as department climate.

\begin{tabular}{|c|c|c|c|c|c|}
\hline \multirow{2}{*}{$\begin{array}{c}\text { Independent } \\
\text { Variable }(X)\end{array}$} & \multirow{2}{*}{$\begin{array}{l}\text { Mediator } \\
\text { (M) }\end{array}$} & \multirow{2}{*}{$\begin{array}{l}\text { Outcome } \\
\text { (Y) }\end{array}$} & a path & b path & c path \\
\hline & & & $\mathbf{X} \rightarrow \mathbf{M}$ & $\mathbf{M} \rightarrow \mathbf{Y}$ & $\mathrm{X} \rightarrow \mathrm{Y}$ \\
\hline \multirow{4}{*}{$\begin{array}{l}\text { Usefulness of } \\
\text { Mentoring }\end{array}$} & General Climate & \multirow{4}{*}{$\begin{array}{l}\text { Professional } \\
\text { Satisfaction }\end{array}$} & $B=0.19(0.06)^{* *}$ & $B=0.49(0.04)^{* *}$ & $B=0.08(0.03)^{*}$ \\
\hline & Transparency & & $B=0.20(0.05)^{* *}$ & $B=0.51(0.05)^{* *}$ & $B=0.08(0.04)^{*}$ \\
\hline & Gender Equity & & $B=0.03(0.04), n s$ & $B=-0.22(0.08)^{* *}$ & $B=0.19(0.04)^{* *}$ \\
\hline & Race Equity & & $B=-0.01(0.03), n s$ & $B=-0.19(0.10)^{*}$ & $B=0.16(0.04)^{* *}$ \\
\hline \multirow{4}{*}{$\begin{array}{l}\text { Usefulness of } \\
\text { Mentoring }\end{array}$} & General Climate & \multirow{4}{*}{$\begin{array}{l}\text { Thoughts of } \\
\text { Leaving }\end{array}$} & $B=0.18(0.06)^{* *}$ & $B=0.44(0.21)^{*}$ & $B=0.21(0.16), n s$ \\
\hline & Transparency & & $B=0.19(0.05)^{* *}$ & $B=-0.25(0.22) n s$ & $B=0.33(0.16)^{*}$ \\
\hline & Gender Equity & & $B=0.04(0.04), n s$ & $B=-0.19(0.31), n s$ & $B=0.30(0.16)^{*}$ \\
\hline & Race Equity & & $B=0.00(0.03), n s$ & $B=-0.03(0.38), n s$ & $B=0.22(0.16), n s$ \\
\hline
\end{tabular}

Note: $B$ represents unstandardized regression coefficients; numbers in parentheses are standard errors; ns represent nonsignificant regression coefficients; and $C I$ represent $\pm 95 \%$ confidence intervals. Confidence intervals that do not straddle zero are statistically significant whereas confidence intervals that do include zero are nonsignificant. ** $p<0.01, * p<0.05,+p<0.10$.

A second mediational test showed that faculty who evaluated peer mentoring as more useful also perceived faculty governance in their department to be more transparent $(B=0.20, S E=0.05, p<0.01)$, which in turn predicted greater professional satisfaction $(B=0.50, S E=0.05, p<0.01)$. The indirect effect of mentoring on professional satisfaction through transparent decision-making was significant $(B=0.10, S E=0.02, C I=0.05,0.15)$. Perceived gender equity and race equity were not significant mediators (Gender equity: $B=-0.01, S E=0.01, C I=-0.03,0.01$; Race equity: $B=0.00, S E=0.01$, $C I=-0.01,0.02)$. See Table 5 for statistical details.

The relation between mentoring and professional satisfaction through positive department climate was not moderated by faculty gender or by department gender composition (see Table 6 for all statistics). In other words, the benefit of mentoring on professional satisfaction was felt equally by all faculty regardless of their gender and regardless of the gender composition of their department. 
Table 6. Moderated mediation: Effect of mentoring on climate and professional satisfaction, with gender and department gender composition acting as moderating variables.

\begin{tabular}{|c|c|c|c|c|c|c|c|}
\hline \multirow{2}{*}{$\begin{array}{l}\text { Independent } \\
\text { Variable (X) }\end{array}$} & \multirow{2}{*}{$\begin{array}{l}\text { Moderating Variable(s) } \\
\text { (W) }\end{array}$} & \multirow{2}{*}{$\begin{array}{l}\text { Mediator } \\
\text { (M) }\end{array}$} & \multirow{2}{*}{$\begin{array}{l}\text { Outcome } \\
\text { (Y) }\end{array}$} & a path & $a^{\prime}$ path & b path & c path \\
\hline & & & & $\mathrm{X} \rightarrow \mathrm{M}$ & $\mathbf{X}^{*} \mathbf{W} \rightarrow \mathbf{M}$ & $\mathbf{M} \rightarrow \mathbf{Y}$ & $X \rightarrow Y$ \\
\hline \multirow{4}{*}{ Mentoring } & \multirow{4}{*}{$\begin{array}{l}\text { Gender AND Dept. } \\
\text { Gender Comp. }\end{array}$} & General Climate & \multirow{4}{*}{$\begin{array}{c}\text { Professional } \\
\text { Satisfaction }\end{array}$} & $B=-0.12(0.48), n s$ & $B=-0.17(0.16), n s$ & $B=0.49(0.04)^{* *}$ & $B=0.37(0.28), n s$ \\
\hline & & Transparency & & $B=0.20(0.42), n s$ & $B=-0.05(0.14), n s$ & $B=0.49(0.05)^{* *}$ & $B=0.22(0.31), n s$ \\
\hline & & Gender Equity & & $B=0.43(0.29), n s$ & $B=0.07(0.10), n s$ & $B=-0.14(0.09), n s$ & $B=0.40(0.37), n s$ \\
\hline & & Race Equity & & $B=0.30(0.27), n s$ & $B=0.07(0.10), n s$ & $B=-0.21(0.10) *$ & $B=0.49(0.37), n s$ \\
\hline
\end{tabular}

Note: $B$ represents unstandardized regression coefficients; numbers in parentheses are standard errors; ns represent nonsignificant regression coefficients. ${ }^{* *} p<0.01,{ }^{*} p<0.05$. 


\subsubsection{Mentoring as Protection against Retention Risk}

We hypothesized that mentoring may act as protection against intentions to leave the university because of improved department climate. To test the hypothesis, we conducted a series of mediational analyses with usefulness of mentoring as an independent variable, intentions of leaving the university as a dependent variable and the four department climate variables as mediators in four separate analyses (see Figure 3). Results showed that increased usefulness of mentoring significantly predicted favorable perceptions of overall department climate $(B=0.18, S E=0.06, p<0.01)$, which in turn predicted lower intentions to leave the university $(B=0.44, S E=0.21, p=0.04)$. The indirect effect of mentoring usefulness on intentions to leave through department climate as a mediator was significant $(B=0.08, S E=0.04, C I=0.03,0.19)$. Decision-making transparency, perceived gender equity, and race equity were not significant mediators. See Table 5 for statistical details.

\section{Discussion}

Scientific discovery requires a workforce that is professionally engaged and satisfied, which depends, in part, on the culture and climate in STEM departments. Our research sought to test three hypotheses aimed at understanding how the climate in STEM departments is influenced by the demographic composition of faculty in those units, how department climate influences faculty outcomes, and possible remedies. Specifically, we hypothesized: (1) Gender of faculty in academic science and engineering and variations in department gender composition would influence workplace climate, faculty members' professional satisfaction, and intentions to stay at or leave the institution; (2) Variations in workplace climate would mediate and explain why unbalanced department gender composition has detrimental impacts on professional satisfaction and turnover intentions; and (3) faculty mentoring may serve as a successful intervention to improve department climate and, in turn, improve professional satisfaction and turnover.

Regarding the first hypothesis, we found that women faculty in STEM were less satisfied compared to their male colleagues only in academic departments where women were a small numeric minority. Gender differences in professional satisfaction were largest in STEM departments with less than $25 \%$ women, smaller but statistically significant in STEM departments with 25-35\% women, and nonexistent in STEM departments with close to $50 \%$ women. Whereas previous research had found that women report less professional satisfaction in academia than men (for reviews see (Bozeman and Gaughan 2011; Ceci et al. 2014), our findings add the important caveat that this is only true for organizational units where women faculty are a tiny numeric minority. Professional satisfaction was similar for both genders in gender-balanced departments.

Second, we found that differences between women and men's professional satisfaction in gender-unbalanced departments were mediated by women's perception that the culture and climate in their unit was less collegial, that faculty governance was not transparent, and that men and women in their department were not treated equally. All three aspects of department climate statistically explained women's lower satisfaction in gender-unbalanced departments. Our findings contribute to previous research on this topic (August and Waltman 2004; Britton et al. 2012; Corley 2005; Fox 2010; Greene et al. 2010; Massachusetts Institute of Technology Committee on Women Faculty 1999) by showing that not all STEM departments are the same. Departments with small proportions of women (10-35\%) were ones where the organizational climate was viewed as least collegial, least transparent, and least equitable, which in turn predicted less professional satisfaction.

Low collegiality also predicted more thoughts of leaving the university among women compared to men. Specifically, women in departments with fewer women $(<35 \%)$ were more likely than their male counterparts to have considered leaving. But in departments that were numerically closer to gender parity (35-54\%) all faculty members, regardless of gender, perceived the climate to be more positive, felt more professionally satisfied, and had infrequent thoughts of leaving the university. Moreover, while numeric gender parity helped women's professional satisfaction it did not hurt men's satisfaction, unlike some past studies (Collins 1998; Etzkowitz et al. 2000; Henwood 1996; Kirchmeyer 1995). Thus, 
our study supports Kanter's theory that as organizations approach gender parity, organizational climate and employee outcomes improve. But different from Kanter's critical mass prediction, we found a linear effect (rather than a sharp inflection) such that as gender composition became less unbalanced, department climate, professional satisfaction, and retention risk all improved in a linear way. In this regard, our findings support Hillard et al. (2014), who proposed that gender composition has a linear effect on faculty outcomes, rather than a sharp inflection based on a specific critical mass. A productive direction for future research would be to recruit faculty from multiple universities to test if this finding generalizes across institutions.

Finally, we sought to address whether faculty mentoring in departments can improve professional satisfaction and reduce retention risk. Our data show that faculty who had in-department mentors and found mentoring to be useful, were more likely to experience their department climate as collegial, which consequently predicted more professional satisfaction and less retention risk. Notably, faculty gender and gender composition did not moderate these findings, suggesting that mentoring was equally effective for all faculty members at improving professional satisfaction and reducing retention risk, regardless of department gender composition. These findings agree with previous research suggesting that mentoring is equally important for all faculty members regardless of gender (Boice 1993; Feldman et al. 2010; Riffle et al. 2013).

A lack of respondents who had only female mentors prevented us from testing whether the benefit of mentoring in STEM departments depends on a gender-match between mentors and mentees. The scarcity of women mentors is not surprising given that women are in the minority in STEM departments, especially at senior levels. Thus, we could not test if women scientists and engineers benefit equally from having male or female faculty mentors or if same-gender mentoring relationships are more effective (Dasgupta 2011; Dennehy and Dasgupta 2017; Dreher and Cox 1996; Ensher and Murphy 1997; Ragins and McFarlin 1990; Ragins and Sundstrom 1989; Settles et al. 2007; Wallace 2001). This is an important topic for future research.

Another avenue of future research is to explore whether the experience of being mentored varies as a function of intersectional race and gender identities. Because only $18.5 \%$ of our sample were faculty of color, we were unable to statistically test whether the relation between mentoring and professional satisfaction or turnover risk depends on a combination of faculty gender and race. Some qualitative research suggests that mentoring experiences of women faculty of color in STEM include some positive, some negative, and some ambivalent components (Buzzenell et al. 2015). However, this former study did not compare the experiences of women of color relative to White women in STEM, which remains a gap in the literature that needs to be addressed in the future.

\subsection{Policy Implications}

Two policy implications emerge from this research. First, our data point to the importance of recruiting and retaining more women scientists and engineers in academic departments with the goal of reaching numeric parity because faculty demographics have robust ripple effects on the collegiality, transparency, and equity in departments. The findings related to retention risk also suggest that departments with the fewest women may have 'revolving doors' such that they are vulnerable to losing the few women faculty they do have, thereby perpetuating problems related to gender inequity.

Second, the positive results for mentoring point to the importance of making faculty mentoring a priority across all departments. For both men and women, even in the most gender-unbalanced departments, mentoring was useful and predicted a collegial and collaborative climate, which in turn predicted greater professional satisfaction and less risk of retention. The fact that mentoring was effective for all faculty members indicates that it should be implemented as broadly as possible. Additionally, our data suggest mentoring is more effective when faculty have opportunities to choose their mentor, rather than having a mentor assigned to them. 


\subsection{Strengths and Limitations}

We highlight four limitations of this research and point to future research avenues that can ameliorate them. First, the present study focused on faculty at one large public university; future research is needed to test the generalizability of these findings to other universities across the nation. For example, will women faculty in physics departments with similar gender composition at other universities have similar perceptions of department climate and similar experiences of professional satisfaction and retention risk? A second limitation is that ours is a correlational study that prevents claims of causation. While experiments testing our hypotheses would be ethically and practically impossible to conduct, future research could test our hypotheses longitudinally to assess whether changes in department demographics over time within the same organizational unit produces subsequent changes in culture and climate, professional satisfaction, and retention risk over time. That type of longitudinal study will nicely complement and replicate the present findings. Third, with regard to mentoring, our survey was unable to test whether or not a gender-match between faculty mentee and mentor would have an added benefit to faculty satisfaction and retention because our sample of senior women faculty mentors was too small. A future study using a larger multi-institution sample would allow an opportunity to investigate this question. Finally, our sample of STEM faculty was more than $80 \%$ White, which limits our understanding of how department gender composition affects women faculty of color in terms of their professional satisfaction and retention risk. Even in departments that approached gender parity, women of color comprised a small numeric minority. Thus their perceptions of department climate, professional satisfaction, and retention risk may be quite different from that of their White female peers. Moreover, faculty of color may be wary of reporting their concerns about department climate or professional satisfaction in surveys after indicating their race because of the concern that their small numbers might make their responses identifiable. Examining the influence of intersectional identities on faculty experiences in STEM as a function of varying department demographics is an important question for future research.

Notwithstanding the limitations, the importance of the present study is that it demonstrates that faculty experiences within different STEM departments are not uniform-gender composition variations among departments have a significant impact on overall department climate, transparency, faculty satisfaction, and attrition. Because of the unique focus on department gender composition, this paper has potential policy implications for universities going forward. First, our data suggest that if university and department leaders increase the numbers of women faculty in specific STEM departments where gender composition is especially unbalanced (e.g., computer science, engineering, physics, astronomy etc.) it is likely to yield big dividends in improved faculty satisfaction and reduced retention risk. Such recruitment may be more effective if done in clusters to prevent a 'revolving door' of attrition. Second, our data identifies mentoring as a possible remedy for the risks associated with gender inequity, suggesting that immediate changes could be implemented to limit attrition and improve workplace satisfaction for both men and women.

Supplementary Materials: The following are available online at http:/ / www.mdpi.com/2076-0760/7/5/71/s1: Original questions from survey instrument.

Author Contributions: Nilanjana Dasgupta conceptualized the study; Eric Griffith and Nilanjana Dasgupta created the survey instrument; Eric Griffith performed the data analysis; Eric Griffith and Nilanjana Dasgupta wrote the paper.

Acknowledgments: We are immensely grateful to all STEM faculty for taking the time to participate in this research. We are grateful to former Dean Steve Goodwin and former Associate Dean Sally Powers in the College of Natural Sciences at the University of Massachusetts Amherst for funding this research and assisting with faculty recruitment. We thank Joya Misra and Laurel Smith-Doerr of the Department of Sociology at the University of Massachusetts Amherst for their feedback on the survey instrument.

Conflicts of Interest: The authors declare no conflicts of interest. 


\section{References}

Acker, Joan. 1990. Hierarchies, jobs, bodies: A theory of gendered organizations. Gender \& Society 4: 139-58. [CrossRef]

Allen, Tammy D., Lillian T. Eby, Mark L. Poteet, Elizabeth Lentz, and Lizzette Lima. 2004. Career benefits associated with mentoring for protégés: A meta-analysis. Journal of Applied Psychology 89: 127-36. [CrossRef] [PubMed]

Allmendinger, Jutta, and J. Richard Hackman. 1995. The more, the better? A four-nation study of the inclusion of women in symphony orchestras. Social Forces 74: 423-60. [CrossRef]

August, Louise, and Jean Waltman. 2004. Culture, climate, and contribution: Career satisfaction among female faculty. Research in Higher Education 45: 177-92. [CrossRef]

Bilimoria, Diana, Susan R. Perry, Xiangfen Liang, Eleanor Palo Stoller, Patricia Higgins, and Cyrus Taylor. 2006. How do female and male faculty members construct job satisfaction? The roles of perceived institutional leadership and mentoring and their mediating processes. The Journal of Technology Transfer 31: 355-65. [CrossRef]

Blackwell, Lauren V., Lori Anderson Snyder, and Catherine Mavriplis. 2009. Diverse faculty in STEM fields: Attitudes, performance, and fair treatment. Journal of Diversity in Higher Education 2: 195-205. [CrossRef]

Boice, Robert. 1993. New faculty involvement for women and minorities. Research in Higher Education 34: 291-341. [CrossRef]

Bozeman, Barry, and Monica Gaughan. 2011. Job satisfaction among university faculty: Individual, work, and institutional determinants. The Journal of Higher Education 82: 154-86. [CrossRef]

Britton, Dana M., and Laura Logan. 2008. Gendered organizations: Progress and prospects. Sociology Compass 2: 107-21. [CrossRef]

Britton, Dana M., Chardie L. Baird, Ruth A. Dyer, B. Jan Middendorf, Christa Smith, and Beth A. Montelone. 2012. Surveying the campus climate for faculty: A comparison of the assessments of STEM and non-STEM faculty. International Journal of Gender, Science and Technology 4: 102-22.

Buzzenell, Patrice M., Ziyu Long, Lindsey B. Anderson, Klod Kokini, and Jennifer C. Batra. 2015. Mentoring in academe: A feminist poststructural lens on stories of women engineering faculty of color. Management Communication Quarterly 29: 440-57. [CrossRef]

Callister, Ronda Roberts. 2006. The impact of gender and department climate on job satisfaction and intentions to quit for faculty in science and engineering fields. The Journal of Technology Transfer 31: 367-75. [CrossRef]

Carli, Linda L., Laila Alawa, YoonAh Lee, Bei Zhao, and Elaine Kim. 2016. Stereotypes about gender and science: Women $\neq$ scientists. Psychology of Women Quarterly 40: 244-60. [CrossRef]

Carrigan, Coleen, Kate Quinn, and Eve A. Riskin. 2011. The gendered division of labor among STEM faculty and the effects of critical mass. Journal of Diversity in Higher Education 4: 131-46. [CrossRef]

Ceci, Stephen J., Donna K. Ginther, Shulamit Kahn, and Wendy M. Williams. 2014. Women in academic science: A changing landscape. Psychological Science in the Public Interest 15: 75-141. [CrossRef] [PubMed]

Childs, S., and M. L. Krook. 2008. Critical mass theory and women's political representation. Political Studies 56: 725-36. [CrossRef]

Chung, Kevin C., Jae W. Song, H. Myra Kim, James O. Woolliscroft, Elisabeth H. Quint, Nicholas W. Lukacs, and Margaret. R. Gyetko. 2010. Predictors of job satisfaction among academic faculty members: Do instructional and clinical staff differ? Medical education 44: 985-95. [CrossRef] [PubMed]

Collins, Lynn H. 1998. Competition and contact: The dynamics behind resistance to affirmative action in academe. In Career Strategies for Women in Academe: Arming Athena. Edited by Lynn H. Collins, Joan D. Chrisler and Kathryn Quina. London: Sage Publications, pp. 45-74.

Corley, Elizabeth A. 2005. How Do Career Strategies, Gender, and Work Environment Affect Faculty Productivity Levels in University-Based Science Centers? Review of policy research 22: 637-55. [CrossRef]

Cullen, Deborah L., and Gaye Luna. 1993. Women mentoring in academe: Addressing the gender gap in higher education. Gender and Education 5: 125-37. [CrossRef]

Dasgupta, Nilanjana. 2011. Ingroup experts and peers as social vaccines who inoculate the self-concept: The stereotype inoculation model. Psychological Inquiry 22: 231-46. [CrossRef] 
Dasgupta, Nilanjana, and Jane G. Stout. 2014. Girls and women in science, technology, engineering, and mathematics: STEMing the tide and broadening participation in STEM careers. Policy Insights from the Behavioral and Brain Sciences 1: 21-29. [CrossRef]

Dennehy, Tara C., and Nilanjana Dasgupta. 2017. Female peer mentors early in college increase women's positive academic experiences and retention in engineering. Proceedings of the National Academy of Sciences of the United States of America 114: 5964-69. [CrossRef] [PubMed]

Dreher, George F., and Taylor H. Cox Jr. 1996. Race, gender, and opportunity: A study of compensation attainment and the establishment of mentoring relationships. Journal of Applied Psychology 81: 297-308. [CrossRef] [PubMed]

Ensher, Ellen A., and Susan E. Murphy. 1997. Effects of race, gender, perceived similarity, and contact on mentor relationships. Journal of Vocational Behavior 50: 460-81. [CrossRef]

Etzkowitz, Henry, Carol Kemelgor, and Brian Uzzi. 2000. Athena Unbound: The Advancement of Women in Science and Technology. Cambridge: Cambridge University Press.

Feldman, Mitchell. D., Patricia A. Arean, Sally J. Marshall, Mark Lovett, and Patricia O'Sullivan. 2010. Does mentoring matter: Results from a survey of faculty mentees at a large health sciences university. Medical Education Online 15. [CrossRef] [PubMed]

Fox, Mary F. 2010. Women and men faculty in academic science and engineering: Social-organizational indicators and implications. American Behavioral Scientist 53: 997-1012. [CrossRef]

Gardiner, Maria, Marika Tiggemann, Hugh Kearns, and Kelly Marshall. 2007. Show me the money! An empirical analysis of mentoring outcomes for women in academia. Higher Education Research E Development 26: 425-42. [CrossRef]

Gardner, Susan K. 2012. "I couldn't wait to leave the toxic environment": A mixed methods study of women faculty satisfaction and departure from one research institution. NASPA Journal about Women in Higher Education 5: 71-95. [CrossRef]

Greene, Jessica, Jean Stockard, Priscilla Lewis, and Geraldine Richmond. 2010. Is the academic climate chilly? The views of women academic chemists. Journal of Chemical Education 87: 381-85. [CrossRef]

Hayes, Andrew F. 2013. Introduction to Mediation, Moderation, and Conditional Process Analysis: A Regression-Based Approach. New York: Guilford Press.

Heilman, Madeline E. 1980. The impact of situational factors on personnel decisions concerning women: Varying the sex composition of the applicant pool. Organizational Behavior and Human Performance 26: 386-95. [CrossRef]

Henwood, Flis. 1996. WISE choices? Understanding occupational decision-making in a climate of equal opportunities for women in science and technology. Gender and Education 8: 199-214. [CrossRef]

Hillard, Amy L., Tamera R. Schneider, Sarah M. Jackson, and David LaHuis. 2014. Critical Mass or Incremental Change? The Effects of Faculty Gender Composition in STEM. In Gender Transformation in the Academy. Edited by Vasilikie Demos, Catherine White Berheide and Marcia Texler Segal. Bingley: Emerald Group Publishing Limited, pp. 355-74.

Hurtado, S. 1998. Texas A \& M University Campus Climate Survey: A Study of Faculty Views and Experiences. Ann Arbor: CSHPE, School of Education, University of Michigan.

Kanter, Rosabeth Moss. 1977. Some effects of proportions on group life: Skewed sex ratios and responses to token women. American Journal of Sociology 82: 965-90. [CrossRef]

Kemelgor, Carol, and Henry Etzkowitz. 2001. Overcoming isolation: Women's dilemmas in American academic science. Minerva 39: 153-74. [CrossRef]

Kirchmeyer, Catherine. 1995. Demographic similarity to the work group: A longitudinal study of managers at the early career stage. Journal of Organizational Behavior 16: 67-83. [CrossRef]

Kram, Kathy E., and Lynn A. Isabella. 1985. Mentoring alternatives: The role of peer relationships in career development. Academy of Management Journal 28: 110-32. [CrossRef]

Long, J. Scott, and Mary Frank Fox. 1995. Scientific careers: Universalism and particularism. Annual Review of Sociology 21: 45-71. [CrossRef]

Lortie-Lussier, Monique, and Natalie Rinfret. 2002. The Proportion of Women Managers: Where Is the Critical Mass? Journal of Applied Social Psychology 32: 1974-91. [CrossRef]

Maranto, Cheryl L., and Andrea EC Griffin. 2011. The antecedents of a 'chilly climate'for women faculty in higher education. Human Relations 64: 139-59. [CrossRef] 
Massachusetts Institute of Technology Committee on Women Faculty. 1999. A Study of the Status of Women Faculty in Science at MIT: How a Committee on Women Faculty Came to Be Established by the Dean of the School of Science, What the Committee and the Dean Learned and Accomplished, and Recommendations for the Future. Cambridge: Massachusetts Institute of Technology.

Michelmore, Katherine, and Sharon Sassler. 2016. Explaining the Gender Wage Gap in STEM: Does Field Sex Composition Matter? RSF: The Russell Sage Foundation Journal of the Social Sciences 2: 194-215. [CrossRef]

Mullen, Carol A., and Janice L. Hutinger. 2008. At the tipping point? Role of formal faculty mentoring in changing university research cultures. Journal of In-service Education 34: 181-204. [CrossRef]

National Science Foundation. 2013. Survey of Doctorate Recipients; Arlington: National Science Foundation. Available online: https://ncsesdata.nsf.gov/datatables/doctoratework/2013/html/SDR2013_DST17.html (accessed on 8 February 2017).

Nosek, Brian A., Mahzarin Banaji, and Anthony G. Greenwald. 2002. Harvesting implicit group attitudes and beliefs from a demonstration web site. Group Dynamics: Theory, Research, and Practice 6: 101-15. [CrossRef]

Ong, Maria, Carol Wright, Lorelle Espinosa, and Gary Orfield. 2011. Inside the double bind: A synthesis of empirical research on undergraduate and graduate women of color in science, technology, engineering, and mathematics. Harvard Educational Review 81: 172-209. [CrossRef]

Pelled, Lisa Hope. 1996. Demographic diversity, conflict, and work group outcomes: An intervening process theory. Organization Science 7: 615-31. [CrossRef]

Pfeffer, Jeffrey, and Alison Davis-Blake. 1987. The effect of the proportion of women on salaries: The case of college administrators. Administrative Science Quarterly 32: 1-24. [CrossRef]

Ragins, Belle Rose. 1999. Gender and mentoring relationships: A review and research agenda for the next decade. In Handbook of Gender and Work. Edited by Gary N. Powell. Thousand Oaks: Sage Publications, Inc., pp. 347-70.

Ragins, Belle Rose, and Dean B. McFarlin. 1990. Perceptions of mentor roles in cross-gender mentoring relationships. Journal of Vocational Behavior 37: 321-39. [CrossRef]

Ragins, Belle Rose, and Eric Sundstrom. 1989. Gender and power in organizations: A longitudinal perspective. Psychological Bulletin 105: 51-88. [CrossRef]

Reskin, Barbara F., Debra B. McBrier, and Julie A. Kmec. 1999. The determinants and consequences of workplace sex and race composition. Annual Review of Sociology 25: 335-61. [CrossRef]

Riffle, Rebecca, Tamera Schneider, Amy Hillard, Emily Polander, Sarah Jackson, Peggy DesAutels, and Michele Wheatly. 2013. A mixed methods study of gender, STEM department climate, and workplace outcomes. Journal of Women and Minorities in Science and Engineering 19: 227-43. [CrossRef]

Sackett, Paul R., Cathy L. DuBois, and Ann W. Noe. 1991. Tokenism in performance evaluation: The effects of work group representation on male-female and White-Black differences in performance ratings. Journal of Applied Psychology 76: 263-67. [CrossRef]

Sands, Roberta G., L. Alayne Parson, and Josann Duane. 1991. Faculty mentoring faculty in a public University. The Journal of Higher Education 62: 174-93. [CrossRef]

Settles, Isis H., Lilia M. Cortina, Janet Malley, and Abigail J. Stewart. 2006. The climate for women in academic science: The good, the bad, and the changeable. Psychology of Women Quarterly 30: 47-58. [CrossRef]

Settles, Isis H., Lilia M. Cortina, Abigai. J. Stewart, and Janet Malley. 2007. Voice matters: Buffering the impact of a negative climate for women in science. Psychology of Women Quarterly 31: 270-81. [CrossRef]

Sorcinelli, Mary D., and Jung Yun. 2007. From mentor to mentoring networks: Mentoring in the new academy. Change: The Magazine of Higher Learning 39: 58-61. [CrossRef]

South, Scott J., Charles M. Bonjean, William T. Markham, and Judy Corder. 1982. Social structure and intergroup interaction: Men and women of the federal bureaucracy. American Sociological Review 47: 587-99. [CrossRef]

Tolbert, Pamela S., Tal Simons, Alice Andrews, and Jaehoon Rhee. 1995. The effects of gender composition in academic departments on faculty turnover. ILR Review 48: 562-79. [CrossRef]

Torchia, Mariateresa, Andrea Calabrò, and Morten Huse. 2011. Women directors on corporate boards: From tokenism to critical mass. Journal of Business Ethics 102: 299-317. [CrossRef]

Tsui, Anne S., Terri D. Egan, and Charles A. O’Reilly III. 1992. Being different: Relational demography and organizational attachment. Administrative Science Quarterly 37: 549-79. [CrossRef]

Wallace, Jean E. 2001. The benefits of mentoring for female lawyers. Journal of Vocational Behavior 58: 366-91. [CrossRef] 
Waltman, Jean Ann. 2001. Mentoring and Academic Success for Women Faculty Members at Research Universities. Doctoral dissertation, University of Michigan, Ann Arbor, MI, USA. (Dissertation Abstracts International, UMI: 3001063).

Wasserstein, Alan G., D. Alex Quistberg, and Judy A. Shea. 2007. Mentoring at the University of Pennsylvania: results of a faculty survey. Journal of General Internal Medicine 22: 210-14. [CrossRef] [PubMed]

Wharton, Amy S., Thomas Rotolo, and Sharon R. Bird. 2000. Social context at work: A multilevel analysis of job satisfaction. Sociological Forum 15: 65-90. [CrossRef]

$\mathrm{Xu}$, Yonghong Jade. 2008. Gender disparity in STEM disciplines: A study of faculty attrition and turnover intentions. Research in Higher Education 49: 607-24. [CrossRef]

Zellers, Darlene F., Valerie M. Howard, and Maureen A. Barcic. 2008. Faculty mentoring programs: Reenvisioning rather than reinventing the wheel. Review of Educational Research 78: 552-88. [CrossRef]

2018 by the authors. Licensee MDPI, Basel, Switzerland. This article is an open access article distributed under the terms and conditions of the Creative Commons Attribution (CC BY) license (http://creativecommons.org/licenses/by/4.0/). 